\title{
Genetic algorithm embedded into a quality-oriented workflow of methods for the development of a linear drive used in intralogistic systems
}

\author{
Linus Wörner ${ }^{1}$, Stefan Kulig ${ }^{1}$, Marén Willing ${ }^{2}$, Petra Winzer ${ }^{2}$ \\ ${ }^{1}$ TU Dortmund University \\ Chair of Electrical Drives and Mechatronics \\ Emil-Figge-Str. 70, 44227 Dortmund, Germany \\ e-mail:linus.woerner@tu-dortmund.de \\ ${ }^{2}$ Bergische Universität Wuppertal \\ Faculty of Civil Engineering, Safety Engineering \\ Research Group Product Safety and Quality Engineering \\ Gaußstrasse 20, 42119 Wuppertal, Germany \\ tel.: +49202/4392060 \\ e-mail:m.willing@uni-wuppertal.de
}

(Received: 18.08.2014, revised: 24.09.2014)

\begin{abstract}
This paper presents the results of the DFG-project (Deutsche Forschungsgemeinschaft) Q-ELF ("Qualitätsorientierter Methodenworkflow für die Produktneuentwicklung eines Linearantriebs in der Fördertechnik") carried out in cooperation of the TU Dortmund University (support code KU 1307/12-1) with the BUW Wuppertal (support code WI 1234-11/1). The project continues the former project SFB 696 (Sonderforschungsbereich) regarding the Demand Compliant Design (DeCoDe) and the corresponding system model that strengthens the knowledge management to create high-quality mechatronical systems. In contrast to the SFB, which comprised the reverse engineering of a belt conveyor, Q-ELF applied a workflow of methods for quality oriented development on a new product. The DeCoDe ensures a methodical development that connects different engineering domains. This connection is important because the most problems and malfunctions arise at the interface of different domains due to their different notations for example. This approach also enables a methodical comparison of different competing concepts to pick the best suited one. A genetic algorithm is presented to further decrease the design-space. The project was carried out to develop linear drives for intralogistic systems.
\end{abstract}

Key words: DeCoDe, genetic algorithm, intralogistic systems, linear induction machine, system model.

\section{Introduction}

The project objective is the evaluation and expansion of the development method DeCoDe. Within a workflow of methods models from electrical engineering and quality engineering are combined synergetically. 
The focus of the project is on a reproducible and methodical development that is flexible and fast enough to react to changing requirements of the stakeholders. An essential part of the research is the development of an electrical linear drive for the usage in intralogistic systems designed for present and future requirements of the stakeholders. This project applied the DeCoDe (Demand Compliant Design [1]) method for a new product development of electrical linear drives, whereas it was established along with a reverse engineering of belt conveyors in the former project SFB $696^{1}$ [2]. The workflow of methods was developed to combine the DeCoDe method with different methods for the product development like methods from electrical engineering. This results in a large number of questions regarding the workflow of methods and DeCoDe, for example the classification of linear drives compared to the mechatronical system or the inheritance of element properties and element relationships among each other.

A secondary objective of the project is the reproducible identification of the best suited linear drive, the traceable documentation of the development process and the integration of additional methods. During the development process, different concepts of linear drives were methodically and reproducible compared to each other regarding their fulfillment of the requirements and the design-space could be iteratively reduced. The best suited concept was identified, designed and further developed afterwards.

During the project, several steps were taken, which also represent the different phases of the project:

- Phase 1. Analytical phase (identification of stakeholder requirements, investigation regarding the usability of linear drives and their potential improvement for intralogistic systems) - Chapter 2.

- Phase 2. Depiction of the investigated requirements and initial research to reduce the design space - Chapter 3.

- Phase 3. Method oriented design process of a linear drive, documentation using the DeCoDe method and further development of the DeCoDe method - Chapter 4.

- Phase 4. Continuous documentation of all decisions and problems during the development process, using the DeCoDe system model - Chapter 5.

\section{Phase 1. Analytical phase}

Linear drives tend to be used rather rarely in logistical systems, despite of their proven superiority regarding specific requirements (e.g. reduction of wear). To ensure a systematical and methodical development process, these requirements had to be verified. Knowledge and experience from the SFB 696 have been further developed, to ensure a reproducible and integral development.

An industry survey was conducted to gather the requirements for intralogistic systems. The gathered information was crucial, because it was needed as a solid foundation on which the product development process could take place. The survey was preferred over a few interviews to ensure a statistically sound basis. It was shown without any doubt that the reliability

\footnotetext{
${ }^{1}$ SFB 696: Forderungsgerechte Auslegung von intralogistischen Systemen - Logistics on Demand.
} 
of the intralogistic systems has top priority. It is, in fact, even more important than running or investment costs, as shown in Figure 1. This has to be taken into account for the new acquisition of intralogistic systems. For the Q-ELF project, a second industry survey has been conducted, validating changes in requirements and going into detail for specific requirements and problems within the product development of intralogistic systems. The result of this second survey has been published in the journal "Zeitschrift für wirtschaftlichen Fabrikbetrieb" (ZWF) [3].

Simultaneously, an investigation regarding the usability of linear drives in intralogistic systems was carried out to identify the potential benefits. Just like their rotary counterparts, the most common types of electrical drives are: the linear induction machine (LIM), the linear synchronous machine (LSM) and the linear permanent magnet synchronous machine (LPMSM). But unlike common rotary machines, the primary (stator) and the secondary (rotor) can be the moving part (Fig. 4). Therefore, six different concepts of linear drives exist [4, 5].

In the first phase, the key advantage of linear drives was also depicted: There is no need for force redirecting units (FRU). Without gears and other forms of FRU, linear drives are not subject to wear and have a superior life-span. The elimination of FRU also leads to a higher precision, because less inaccurate elements are used and it leads to a higher possible acceleration due to the smaller mass that has to be moved. It also leads to a higher protection class due to the compact design and makes them best suited for covering large distances (no cardan shafts necessary for example). Unfortunately, the longitudinal end effect (LEE) lessens the efficiency in short-primary LIM for high velocities [5]. Additionally, the investment costs for linear machines are much higher than for rotary machines, due to the bigger number of active sections and permanent-magnets (only for LPMSMs), which have to be installed. The main disadvantage is the lack of a simple implementation method for mechanical brakes. These have to be installed on every moving part in the intralogistic system, whereas a central rotary drive only needs one mechanical brake, which adds even more to the investment costs advantage of rotary machines. The fundamental lower efficiency of linear drives compared to their rotary counterparts makes them less suited for high power applications, too. These applications do not make sense from the economical point of view and this can only be compensated if the application also requires a very high reliability. These advantages and disadvantages have to be taken into account, to identify the field of application, where the usage of a linear drive is preferable to the usage of rotary machines. Considering the results of the industry survey and the investigation regarding the potential of linear drives in intralogistic systems, the currently used system is not as important as the conditions of the environment, where the mechatronic system will be employed.

\section{Phase 2. Depiction of the investigated requirements and initial research to reduce the design space}

Due to the industry survey, it was possible to prioritize the requirements imposed on the drives. This was done using the $\mathrm{LOOMEO}^{2}$ software. Manufacturers and users of linear drives

\footnotetext{
${ }^{2}$ LOOMEO is a software to visualize complex inter relationships (compare www.teseon.de/loomeo).
} 
and users of conveyor lines agree without a doubt that the reliability of the intralogistic system has top priority, as seen in Figure 1.

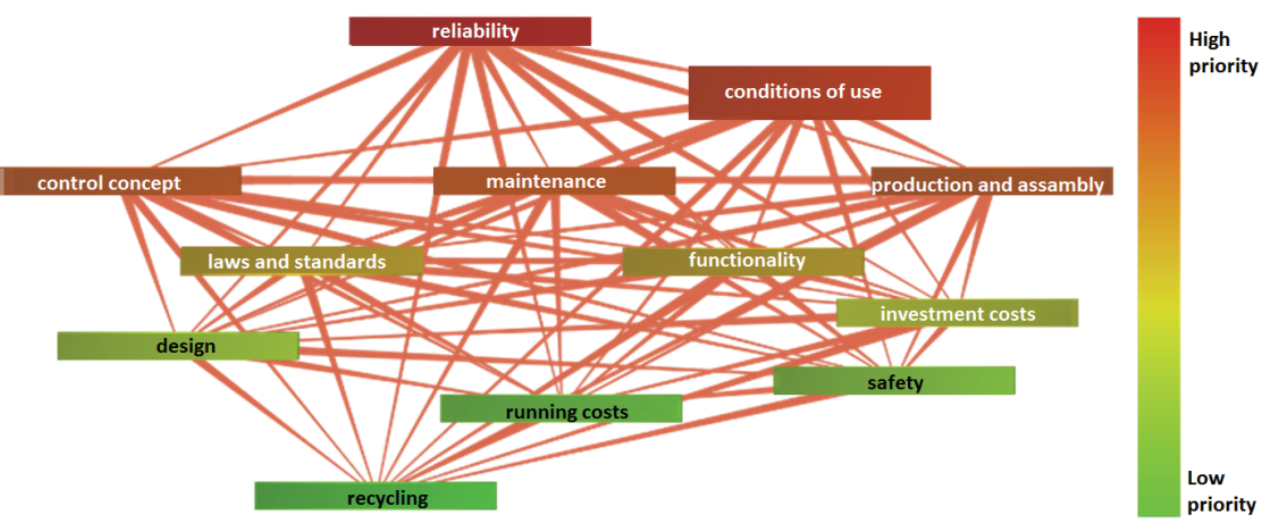

Fig. 1. Prioritized requirements imposed on intralogistic systems

To determine the degree of fulfillment of the requirements of the different concepts, all systems were further depicted in system models presented in Chapter 4 (phase 3). Because of the blurred requirements, unfortunately the forecast of the requirement fulfilment is also vague. Nevertheless, this can be used for a verifiable comparison of different concepts.

To ensure a verifiable comparison of the different concepts, not only the prioritized requirements are needed, but also the field of application. Because of the fact that these drives shall be used in intralogistic systems, properties that hinder their ability to transport consumer goods (like electronics) or restricts their field of application have a negative impact on their suitability.

The main disadvantages for this field of application are the permanent magnets of LPMSMs and the towing cables of short-primary linear drives and short-secondary LSMs. The second impose an additional source for wear and therefore increase the wear inside the intralogistic system, negating the key advantage. Both of these disadvantages will be summarized into the category conditions of use.

Table 1. Parameters of the used equivalent circuit model

\begin{tabular}{l|l}
\hline$X_{1}$ & Primary inductive reactance \\
\hline$X_{2}$ & Secondary inductive reactance \\
\hline$R_{1}$ & Primary resistance \\
\hline$R_{m}$ & LEE modeling resistance \\
\hline$X_{m}$ & Mutual inductive reactance \\
\hline$R_{2}$ & Secondary resistance \\
\hline
\end{tabular}

According to Table 2, the LIM is the best suited drive for intralogistic systems and was further analyzed. The equivalent circuit model (ECM) was used to obtain first information regarding the linear induction machines. It has to be mentioned that the ECM of short-primary 
LIM was modified, using the longitudinal end effect (LEE) elements, regarding [5]. These additional elements are velocity dependent and mimic the field weakening properties of the LEE due to the factor Q and the additional resistor $R_{m}$.

Table 2. Forecast of requirement fulfillment (high: 4, medium: 3, low: 2, none: 1)

\begin{tabular}{l|c|c|c|c|c|c}
\hline & $\begin{array}{c}\text { Short- } \\
\text { primary } \\
\text { LSM }\end{array}$ & $\begin{array}{c}\text { Short- } \\
\text { secondary } \\
\text { LSM }\end{array}$ & $\begin{array}{c}\text { Short- } \\
\text { primary } \\
\text { LIM }\end{array}$ & $\begin{array}{c}\text { Short- } \\
\text { secondary } \\
\text { LIM }\end{array}$ & $\begin{array}{c}\text { Short- } \\
\text { primary } \\
\text { LPMSM }\end{array}$ & $\begin{array}{c}\text { Short- } \\
\text { secondary } \\
\text { LPMSM }\end{array}$ \\
\hline Reliability & 4 & 4 & 4 & 4 & 4 & 4 \\
\hline Conditions of use & 2 & 2 & 2 & 3 & 1 & 1 \\
\hline Maintenance & 3 & 3 & 3 & 3 & 3 & 3 \\
\hline $\begin{array}{l}\text { Production and } \\
\text { assembly }\end{array}$ & 2 & 2 & 3 & 3 & 3 & 3 \\
\hline Functionality & 4 & 4 & 4 & 4 & 4 & 4 \\
\hline investment costs & 3 & 2 & 3 & 2 & 3 & 2 \\
\hline Safety & 3 & 3 & 3 & 3 & 2 & 2 \\
\hline Running costs & 3 & 4 & 3 & 4 & 3 & 4 \\
\hline Sum & 24 & 24 & 25 & 26 & 23 & 23 \\
\hline
\end{tabular}

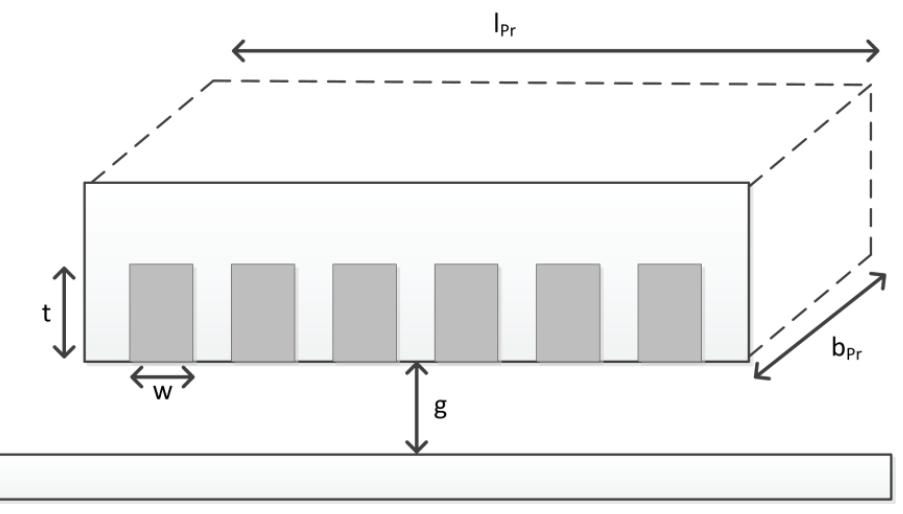

Fig. 2. Geometric parameters

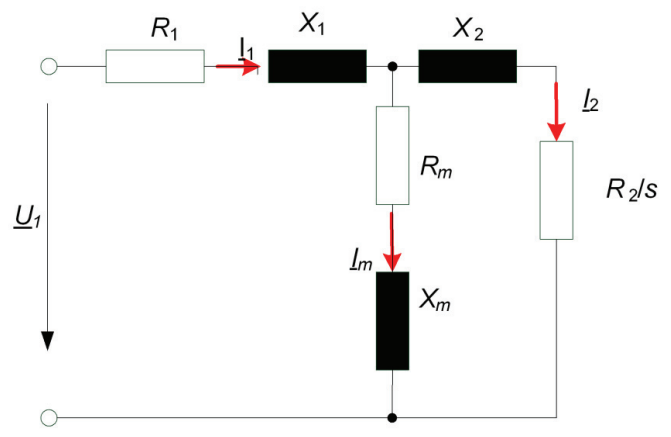

Fig. 3. Modified ECM - short-primary LIM [5] 
The elements of the stationary equivalent circuit model (ECM) of the LIM can be calculated using the geometric parameters (Fig. 2) and the electrical parameters (slot filling factor $K_{f}$, the number of slot windings $N$, pole pitch $\tau_{p}$, number of poles $p$, conductivity of copper $\rho_{c u}$, the number of slots per phase per pole $q$, the relative conductivity $\rho_{r}^{\prime}$, the winding factor $K_{w}$, chording factor $\beta$, winding breath factor $K_{2}$, number of phases $m$ ). The parameters $\lambda_{i}$ have to be calculated separately using:

$$
\begin{aligned}
& \lambda_{c}=\frac{t}{12 w(1+3 \beta)}, \\
& \lambda_{d}=\frac{5 g / w}{5+4 g / w}, \\
& \lambda_{e}=0.3 \cdot(3 \beta-1) .
\end{aligned}
$$

That way an easy calculation of the parameters is fast enough to be used inside a MATLAB code or genetic algorithms. The factor $Q$ is particularly important, because it models the different influence of the velocity dependent longitudinal end effect. It can be seen, that the ECM of a short-secondary LIM (or a short-primary without velocity dependency) is identical to the rotary LIM.

$$
\begin{gathered}
R_{1}=\rho_{c u} \cdot \frac{N^{2} \cdot p \cdot q \cdot\left(2 \tau_{p}+2 b_{\mathrm{Pr}}\right)}{w \cdot t \cdot K_{f}}, \\
R_{2}^{\prime}=\frac{b_{\mathrm{Pr}}}{\tau_{p}} \cdot \rho_{r}^{\prime}\left(K_{w} \cdot N\right)^{2}, \\
R_{m}=R_{2} \cdot\left(\frac{1-e^{-Q}}{Q}\right), \\
X_{1} \approx \frac{2 \mu_{0} \omega}{p}\left(\frac{\left(\lambda_{c}+\lambda_{d}\right) \cdot b_{\mathrm{Pr}}}{q}+\lambda_{c} \frac{\tau_{p}}{\pi} K_{2}^{2} \cdot m\right) \cdot N^{2}, \\
X_{m}=\frac{6 \mu_{0} \omega}{\pi^{2}} \frac{\tau_{p} b_{\mathrm{Pr}}}{p \cdot g}\left(K_{w} \cdot N^{2}\right)^{2} \cdot\left(1-\frac{1-e^{-Q}}{Q}\right), \\
Q=\frac{1_{\mathrm{Pr}} \cdot R_{2}}{\left(L_{m}+L_{2}\right) v} .
\end{gathered}
$$




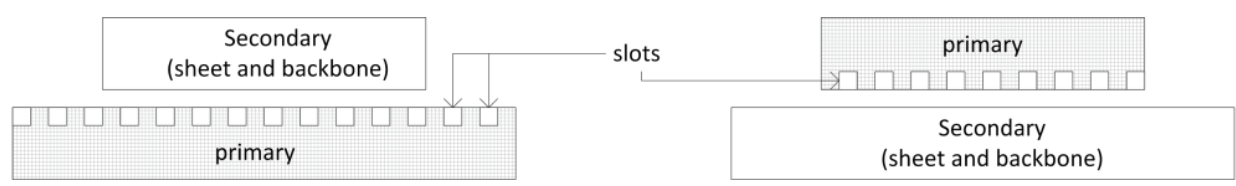

Fig. 4. Comparison short-secondary LIM (left) to short-primary LIM (right)

It has to be underlined that only the short-primary is subject to the LEE. The shortsecondary LIM can be modeled using the standard ECM of induction machines.

This ECM was embedded into a genetic algorithm ${ }^{3}$ to achieve an automated design-space reduction. The properties used were geometrical properties (primary length, slot width, etc.) or electrical parameters (number of pole pairs, etc.). The stakeholder requirements (velocity, size of carrier boxes, etc.) were used as input parameters. A fitness-function had to be established for the genetic algorithm and the effective efficiency was used to calculate a precise number, because of the fact that genetic algorithms rarely work with vague tendencies. The effective efficiency is calculated using the ratio of mechanical power (only using the load) and the input-power (at nominal speed of $2 \mathrm{~m} / \mathrm{s}$ ):

$$
\eta_{\text {eff }}=\frac{P_{\text {Load }}}{P_{\mathrm{IN}}} .
$$

The algorithm was terminated, when five iterations of the population in a row were led by the same (best suited) individual, as shown in Figures 5, 6. Unfortunately, the effective efficiency of the best suited individual does not seem to be consistent for the short-primary experimental series. The short-secondary experimental series seems to be much more consistent. This is a result from the additional dependencies, because of the limiting factor weight of the moving primary.

An increased number of consecutive generations that one individual has to be the best suited individual, increases the probability to escape the local extremum and reach the global extremum (as shown in Fig. 8). A termination after 20 generations lead by the same individual is shown in Figure 7.

Even though the maximum effective efficiency increased, it is still different for several experimental series (there seem to be a local optimum at 12\%). A new experimental series (using 1000 consecutive generations for the best individual) could ensure that a global extremum was reached. This can be claimed due to the similar effective efficiency of the best individual in the different series of experiment (as shown in Fig. 8 a) and b)). Due to the fact that the genetic algorithm uses a heuristic approach to create new individuals, the efficiency curve isn't a gradual increase but rather random, as seen in Fig. 7 d) and Fig. 8 b). Because of that it is important to run several experimental series.

\footnotetext{
${ }^{3}$ A genetic algorithm uses heuristically generated individuals. Every iteration is called a population of the specific generation.
} 
a)

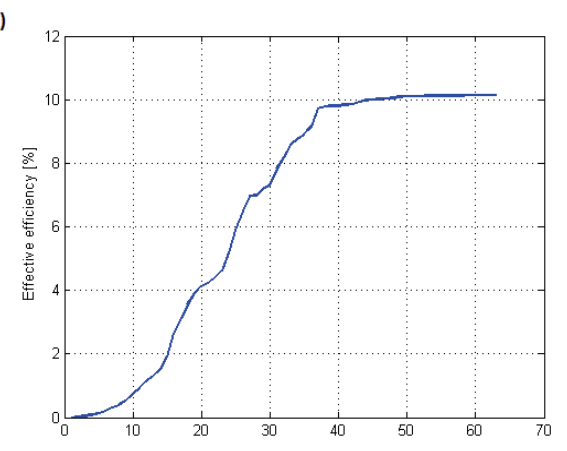

c)

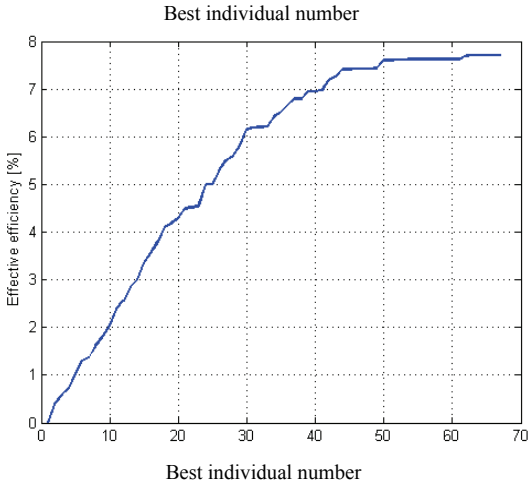

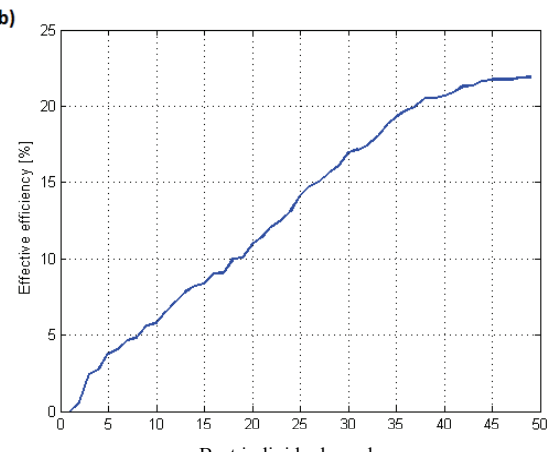

d)

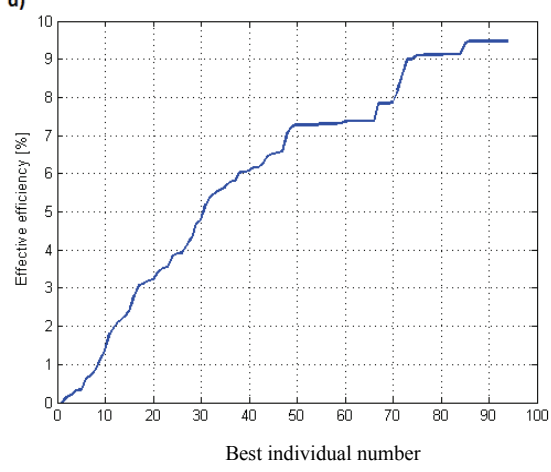

Fig. 5. Short-primary experimental series -5 generation termination

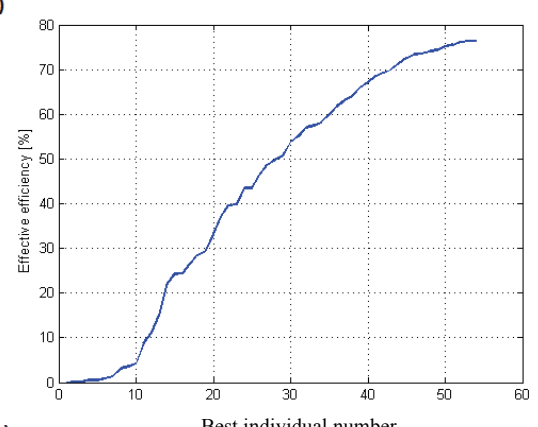

c)

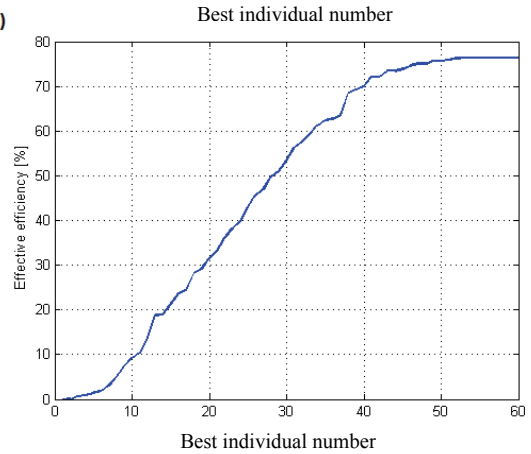

b)

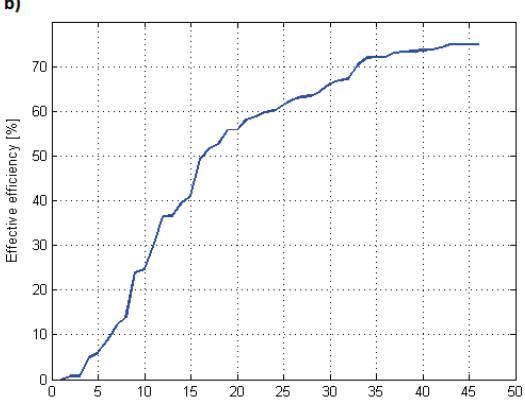

d).

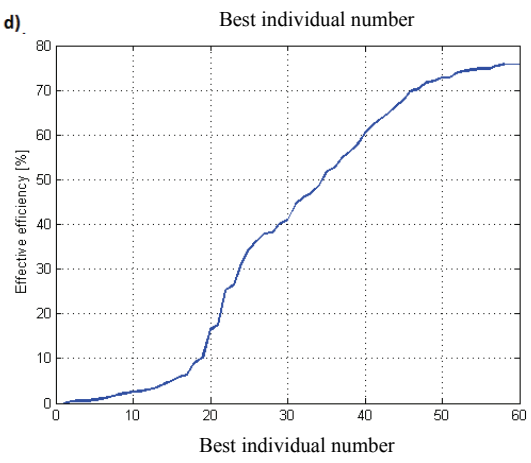

Fig. 6. Short-secondary experimental series -5 generation termination 
a)

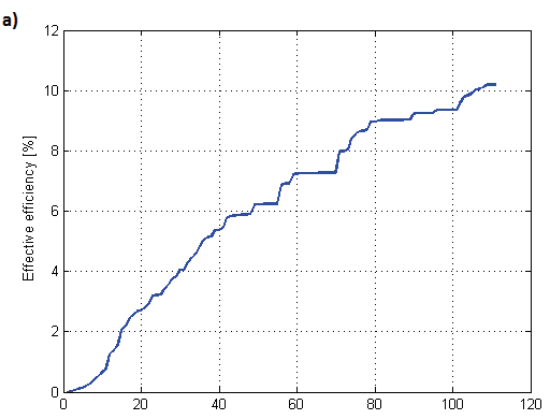

c)

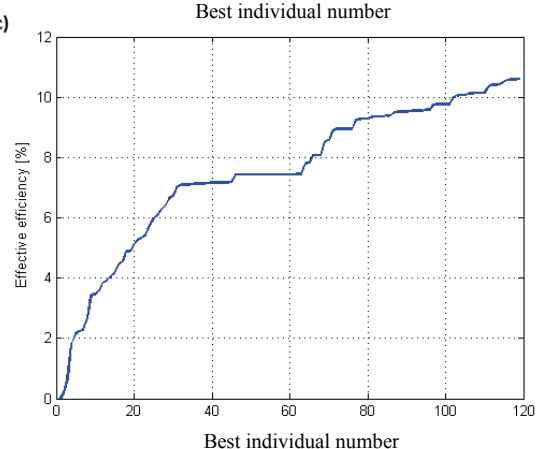

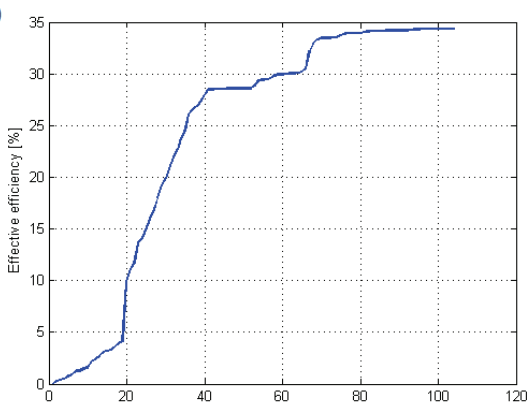

d)

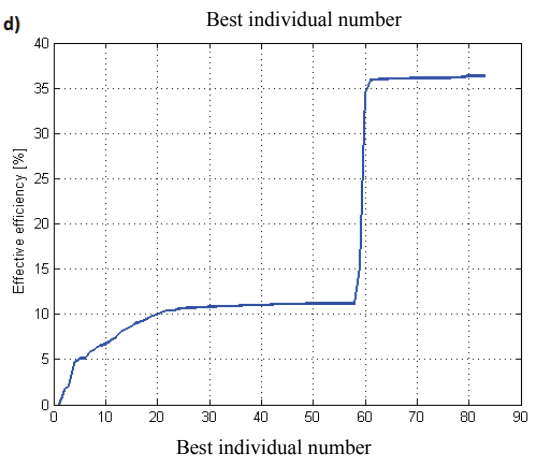

Fig. 7. Short-primary experimental series -20 generation termination

a)
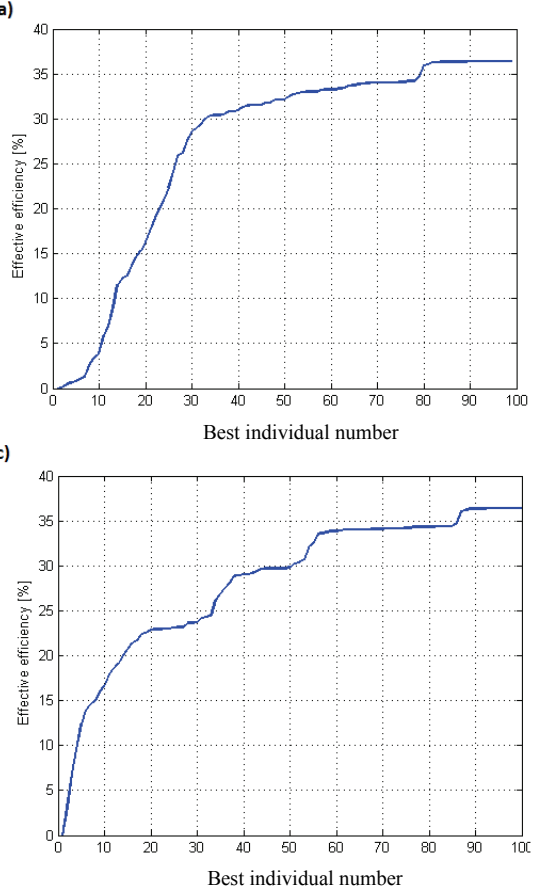

b)

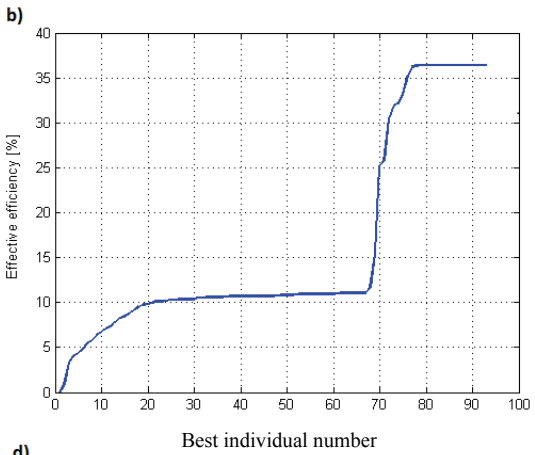

d)

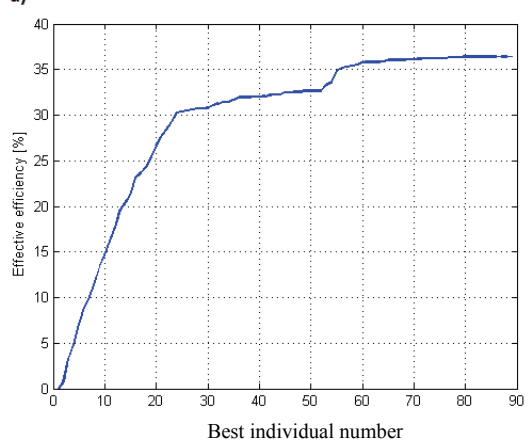

Fig. 8. Short-primary experimental series -1000 generation termination 
Using an intelligent control mechanism that only activates the necessary primaries, it can be shown that the short-secondary LIM is roughly twice as effective as the short-primary, regarding the energy costs. This enables the operator of intralogistic systems to estimate which concept is preferable for his case, but one also has to keep in mind that the short-primary LIM still need additional cables for power input for each moving primary. This adds additional sources prone to wear and reduces the advantage of linear drives.

\section{Phase 3. Method-oriented design process}

As part of the project, the development process using the DeCoDe method and the workflow of methods was documented and improved. To further increase the usability of the workflow of methods the modelling of functions within the DeCoDe system model was progressed. Modelling functions is particularly advantageous in early stages of the development process as they depict the systems purpose in a solution neutral way. Additionally, the topic of heredity of the properties of the functions and of the cause-effect-relationships could be addressed. The developed systems model can be used as a reproducible method to model the function interrelationships.

This function structure was used to model the short-primary and short-secondary LIM to identify potential problematic structures, like bottle-necks, the lack of redundancy as well as system in- and outputs that harm the usability of the linear induction machine etc. This reproducible development process was created to increase the reliability of the mechatronical system.

The modeling process using the functions was done on different levels, starting with level no. 0 (as shown in Fig. 9), where no specifications regarding components are set up, yet. Each successive level represents a specification of the system, because of the definition of specific components that implement the functions. This leads to a gradual reduction of the design space. The function for the elements will be marked with an $F$, whereas the associated component will be marked with an C. As shown in Figure 9 to Figure 11, internal properties (e.g. the electromagnetic field $\underline{B}_{\text {wander }}$ ) will be passed on to each underlying level. Hence this and the fact that the input and output of each function do not reduce the design space and are based on principles of action, the function structure fulfills the requirement of solution neutrality [8]. The splitting of the three-phase connection to three phases (Fig. 10 to Fig. 11) was done to incorporate the trailing cable needed in short-primary linear induction machines. It is the main modeling difference of short-primary and short-secondary linear induction machines. It represents the cables needed to power the linear drive.

In addition to the inheritance of attributes of functions (inputs and outputs) another approach was developed to track the error propagation: Using the underlying hierarchical interrelationships and the material flow, energy flow and information flow, the effects of errors in one part of the model can be tracked to every other part of the model, too. While this is not an actual inheritance problem, it can be used as quasi-heredity to track the error propagation. This information can be used as described in [9]. 
Table 3. Functions categories (cf. [6; 7])

\begin{tabular}{|c|c|c|c|}
\hline Function & Symbol & Meaning & Value/unit \\
\hline channel & & $\begin{array}{l}\text { the function input is conducted; no changes } \\
\text { of value or unit }\end{array}$ & $\begin{array}{l}\text { value: constant } \\
\text { unit: constant }\end{array}$ \\
\hline change & & $\begin{array}{l}\text { the function input is transformed; value and } \\
\text { unit change from input to output }\end{array}$ & $\begin{array}{l}\text { value: varies } \\
\text { unit: varies }\end{array}$ \\
\hline vary & & the value of the function input is reduced & value: varies \\
\hline & & the value of the function input is increased & \\
\hline \multirow{2}{*}{ connect } & & several function inputs are united & \multirow{2}{*}{$\begin{array}{l}\text { value: varies } \\
\text { unit: constant }\end{array}$} \\
\hline & & $\begin{array}{l}\text { the function input is divided into several } \\
\text { function outputs }\end{array}$ & \\
\hline store & & the function input is stored & $\begin{array}{l}\text { value: varies } \\
\text { (regarding time) } \\
\text { unit: constant }\end{array}$ \\
\hline
\end{tabular}

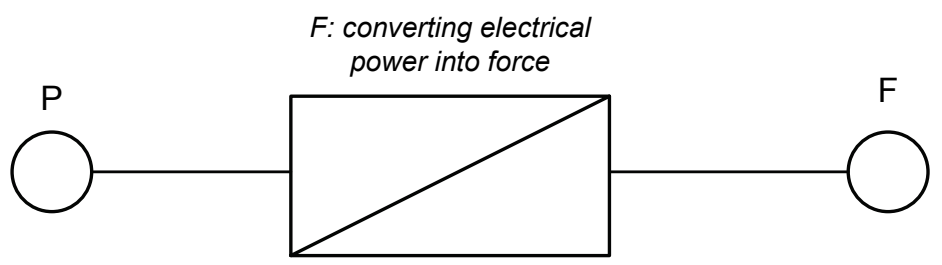

C: Machine

Fig. 9. Function structure (system model) - level no. 0 [6] - specification: electrical machine to generate force

Based on the results of phase 2 (described in Chapter 3) and the function structure a shortsecondary linear induction machine was chosen and the stationary behavior was computed using Finite Element Models. As usually, the requirements of the stakeholders are what the computation is based upon. The ECM (shown in Fig. 3) was used to calculate the input data for the stationary finite element model. 


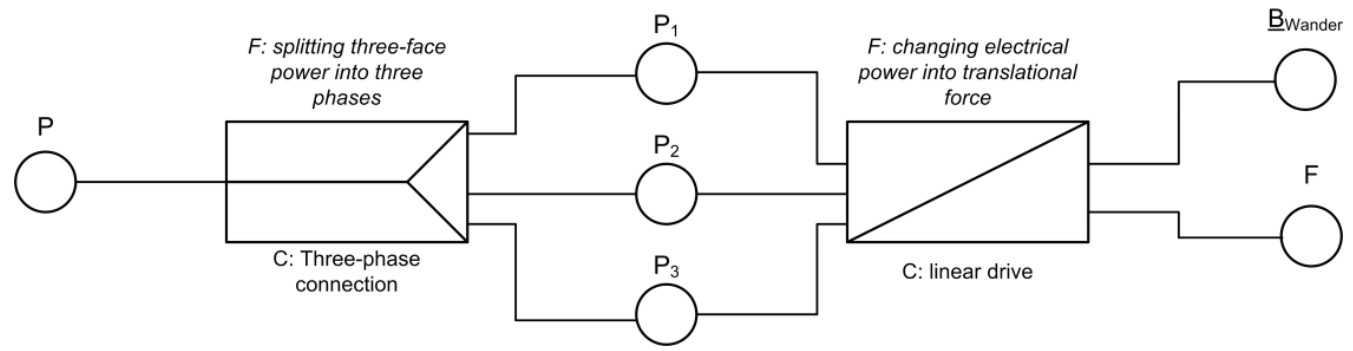

Fig. 10. Function structure (system model) - level no. 1 [6] - specification: generate force with a linear drive

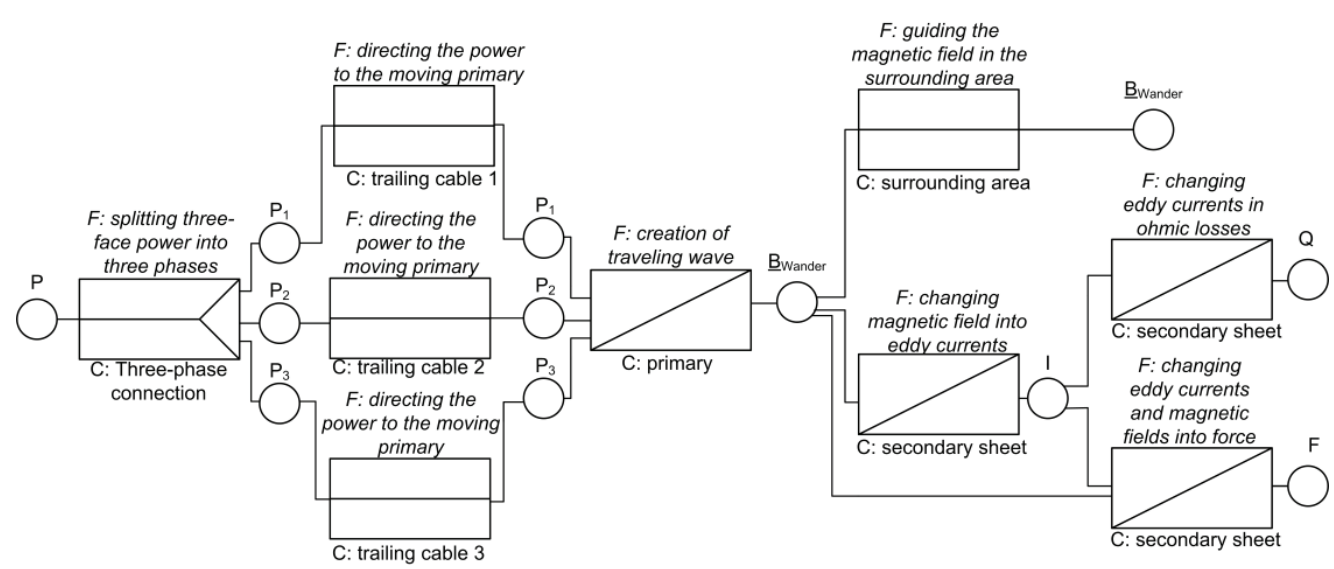

Fig. 11. Function structure (system model) - level no. 2 [6]

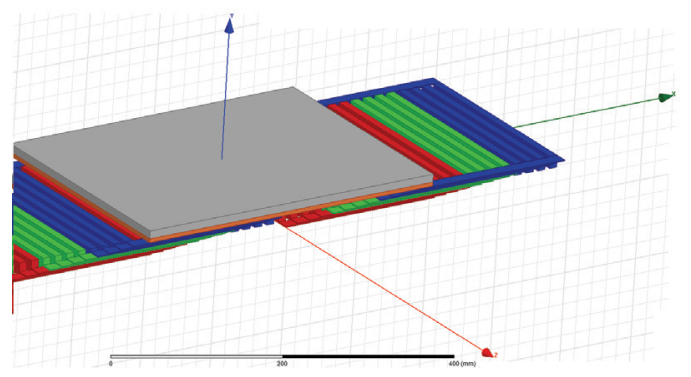

Fig. 12. 3D steady-state model

Based on the information that the function structure was able to provide, the secondary will be prone to a rising of the temperature, because of the eddy currents inside of it. This leads to a steady-state computation of the short-secondary LIM to compute the eddy currents and use them to estimate the temperature of the secondary. 
The used frequencies were modeled to mimic two different operating conditions, standstill and nominal operation condition. The standstill was used as a worst-case scenario with a mechanical error preventing the secondary from moving further, despite of an activated primary (shown in Tab. 4).

Table 4. Supply frequency for different operation conditions

\begin{tabular}{l|c}
\hline \multicolumn{2}{c}{ Supply frequency } \\
\hline Start up $(s=1)$ & $5.8824 \mathrm{~Hz}$ \\
\hline Nominal operating condition $(s=0.15)$ & $0.88236 \mathrm{~Hz}$ \\
\hline
\end{tabular}

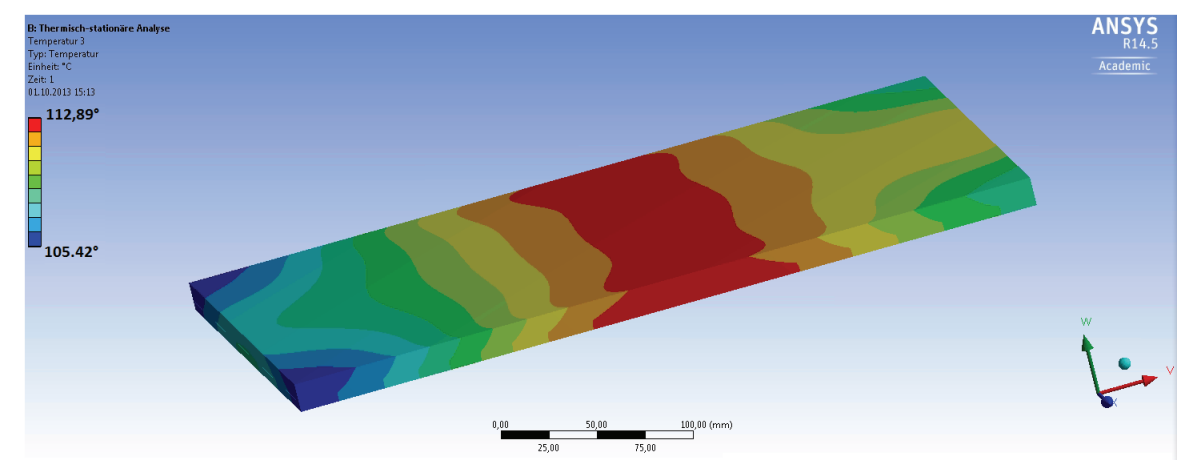

Fig. 13. Temperature - nominal operating condition

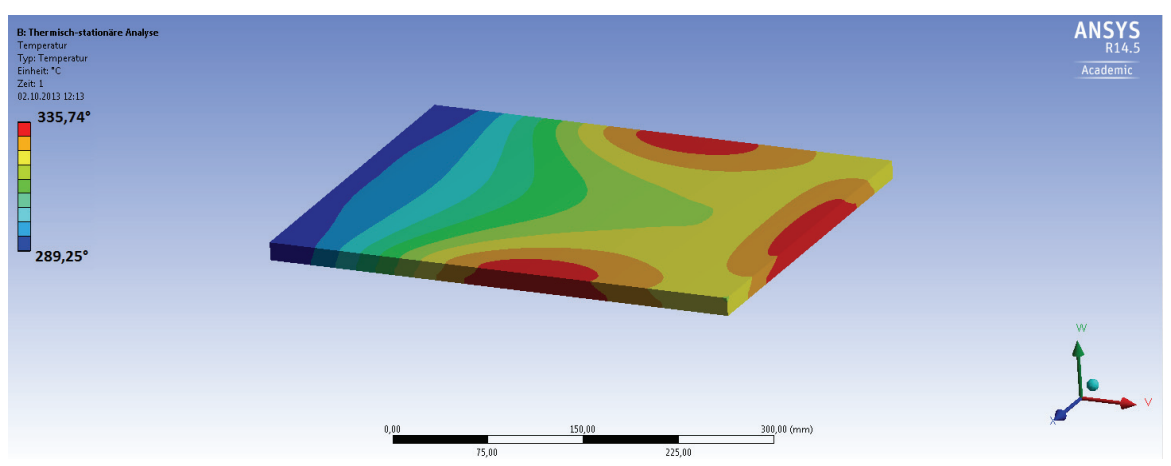

Fig. 14. Temperature - standstill

It can be seen that the temperature is rising above a permissible maximum because it can cause harm to the operating staff or the conveyed goods. To reduce the temperature of the secondary, the process of the heat development and heat dissipation was further analyzed, using the system model once again, because an active cooling systems for a moving secondary would negate the fundamental advantage of the concept because of the necessary connections for the coolant. It can be seen that the heat is transferred through the air as the main heat 
dissipation mechanism. To improve the heat dissipation, the amount of heat that can be transferred has to be increased which would be possible by increasing the surface area of the secondary or increasing the velocity. Because of the fact that the velocity is a requirement of the stakeholders and therefore cannot be changed, only the enlargement of the secondary surface remains, which can be done using cooling fins, as shown in Figure 15.

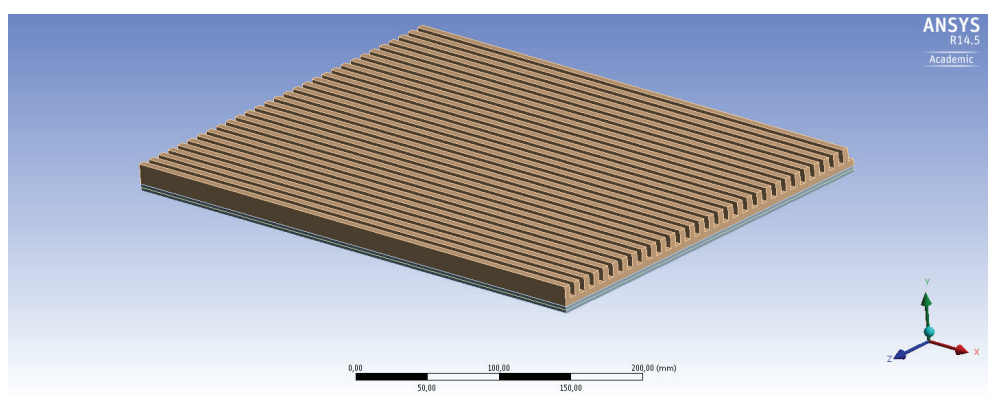

Fig. 15. Cooling fins $-5 \mathrm{~mm}$ width

To avoid additional weight because of the fins, they were formed using the iron backbone itself. That way, no additional mass was added to the short-secondary. The initial adjustment of the backbone was done creating cooling fins with $5 \mathrm{~mm}$ width, more and narrower fins would be able to increase the surface even further. The only limiting factor is the load force of the conveyed goods on top of the secondary. The result is shown in Figure 16 and Figure 17.

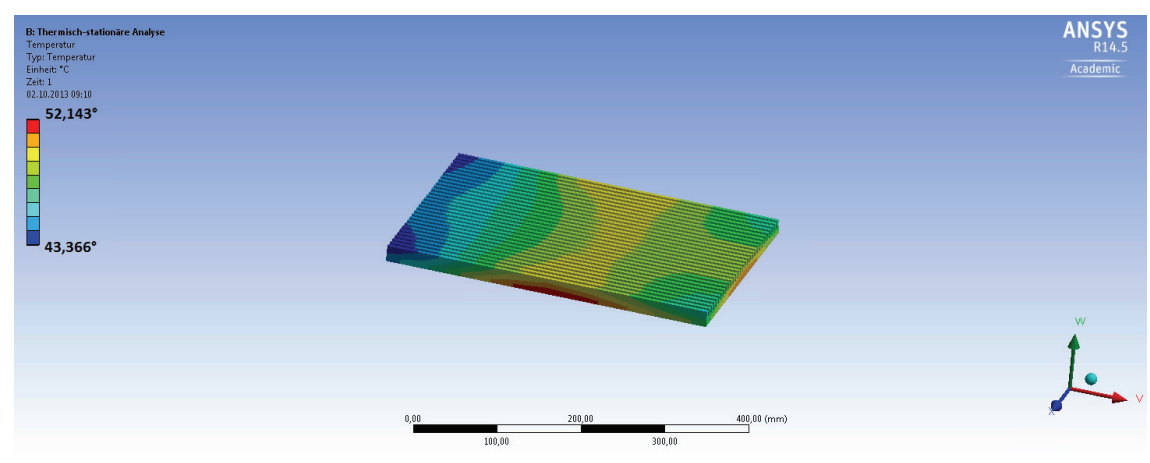

Fig. 16. Temperature - nominal operating condition with cooling fins $(5 \mathrm{~mm})$

Despite the fact that the temperature for the nominal operating condition could be reduced to a tolerable level, the worst-case scenario temperature was still out of limits. Further narrowing the cooling fins is desirable.

Based on the product development process guided by the workflow of methods and inspired by the system model, a sequence of steps could be invented that shows when to use specific simulations and methods, as shown in [4] and Figure 18. 


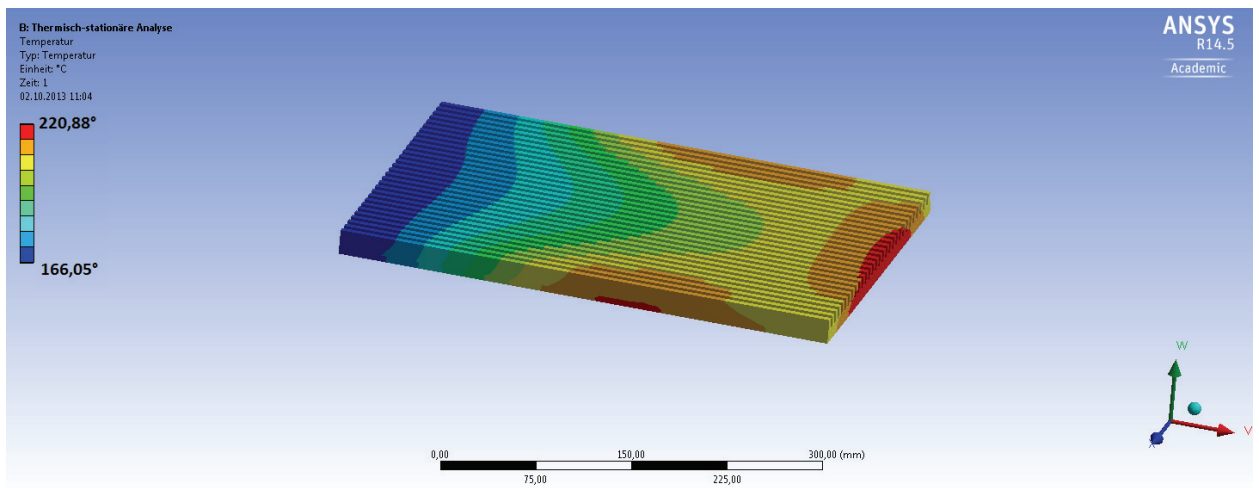

Fig. 17. Temperature - standstill with cooling fins $(5 \mathrm{~mm})$

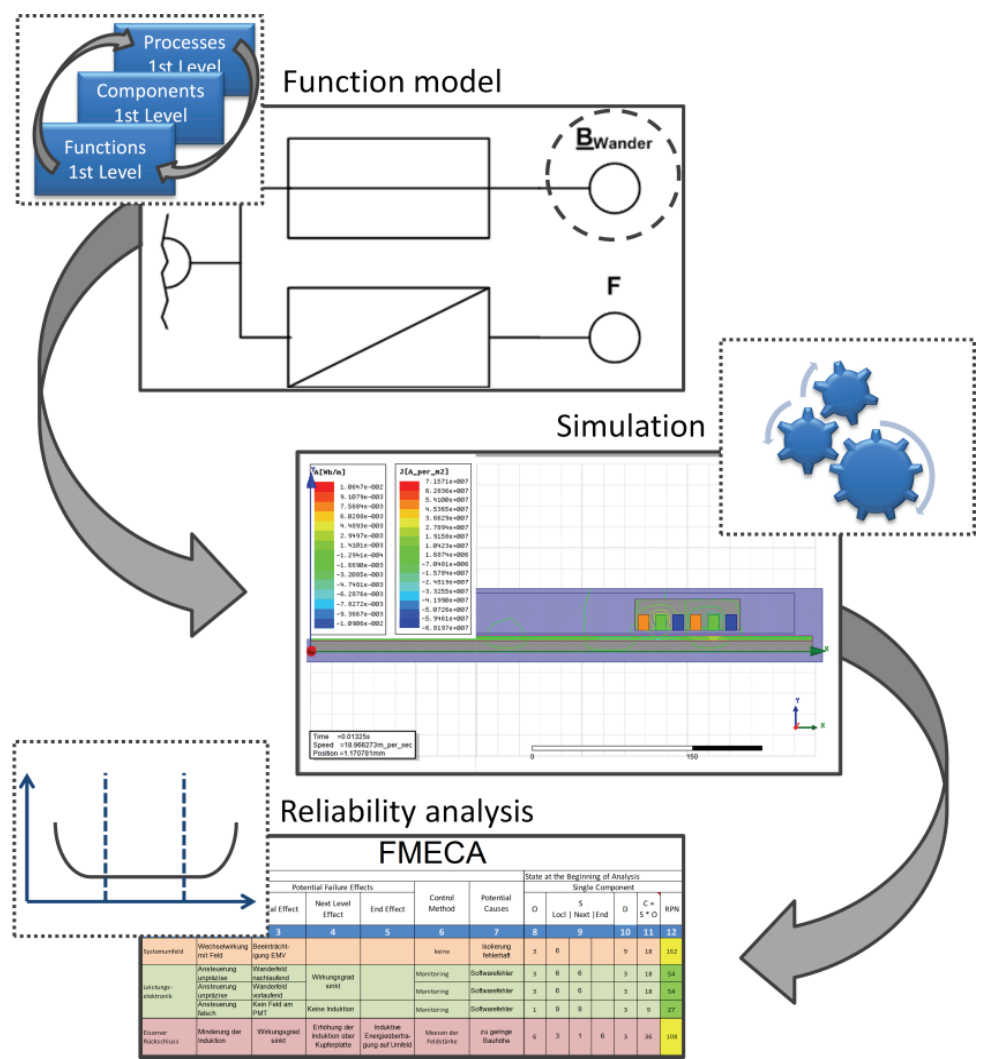

Fig. 18. Usage of the function systems model to embed methods and simulations [4]

The quintessence of this approach is the early identification of disturbances and potential sources of error even before any commitments to specific components are made. The following quantification of these disturbances using simulations in the subsequent phases of the 
product development ensures that none of them is overlooked and therefore lessens the quality of the final product. This also enables the user of this method to optimize the system in the early stages of the product development phases.

The workflow for the integration of methods and simulations is initiated by the identification of physical quantities from the function structure, if these are either not locally restricted (e.g. magnetic field) or have a potentially negative impact on surrounding elements (e.g. heating of the PCB). The insights gained from the simulations serve as a basis for risk assessment and can be used to undertake measures or corrective actions if necessary. This approach verifies and optimizes the workflow of methods developed in the SFB 696 as each of the seven steps is completed (cf. [11], Fig. 19).

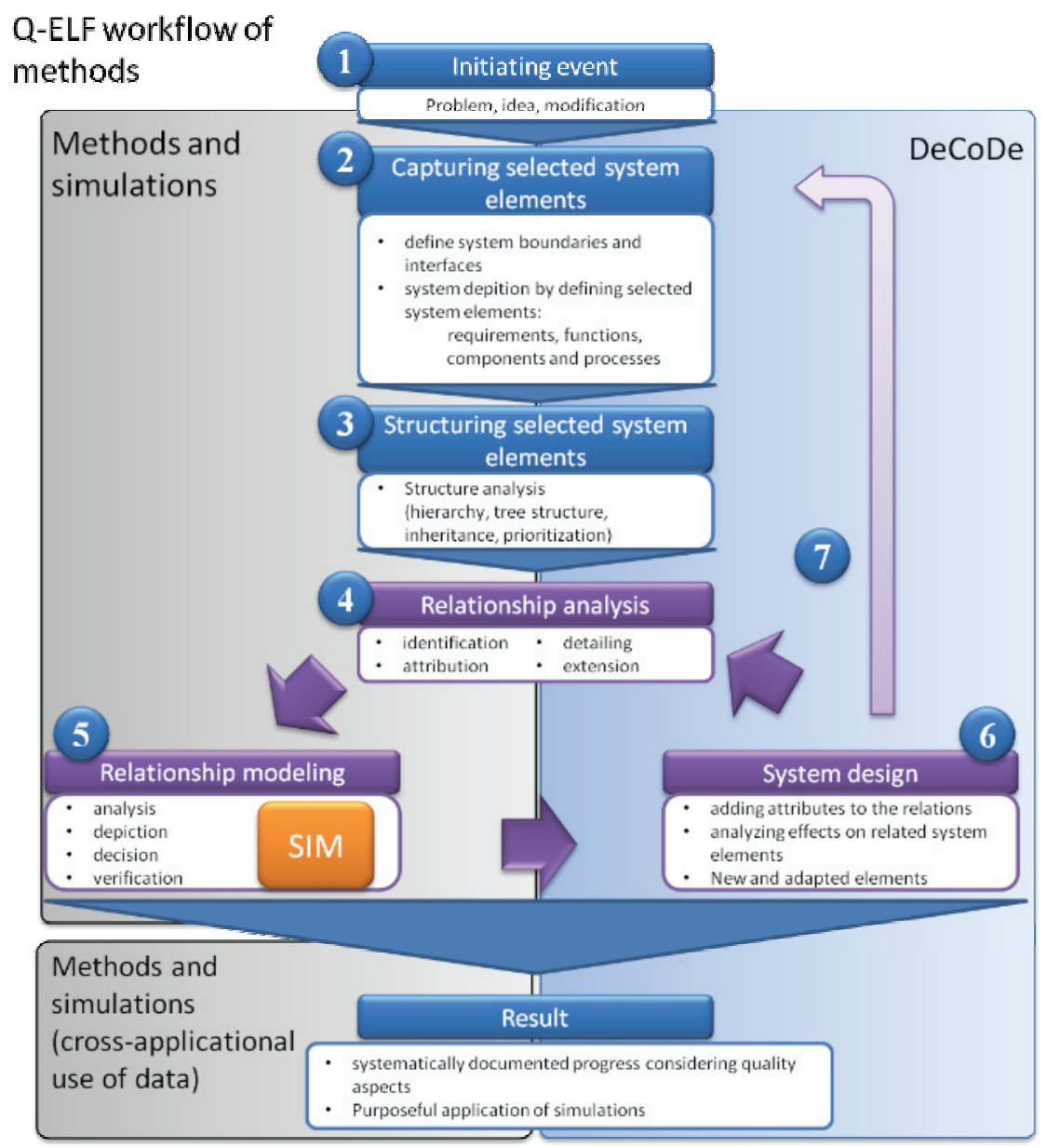

Fig. 19. Optimized workflow of methods (cf. [11])

1) Initiating event is in case of Q-ELF the idea to use linear drives for intralogistic systems.

2) and 3) As a new product shall be developed, the first elements that are captured are functions. Functions allow a solution neutral description and development without binding 
the thinking too early to certain components. Like depicted in Figures 9-11 the function structure becomes more detailed with every new level and the relations for each level are captured right away, before a new level is added. That's why step 2 and 3 are combined in this case. Establishing the function structure for the linear drive it became obvious that thermal energy is released due to the electromagnetic field $\underline{B}_{\text {wander }}$.

4) The objective of relationship analysis is the identification of interrelations between elements of different sights. The previous steps concluded that heat will be generated. Therefore, the components sight needs too be modeled detailed enough to link the function 'Change ohmic losses to thermal energy' with the component 'secondary sheet'.

5) Based on the knowledge that thermal energy is released at the component 'secondary sheet', the FE-method Ansys was applied to determine the quantity of energy (cf. Figs. 13 and 14).

6) The conclusion of step 5 was, that the quantity of thermal energy is not tolerable. This leads to the decision to add cooling fins. This change on the component 'secondary sheet' is integrated in the system model.

7) Now it needs to be analyzed, if the changed component influences other elements of the system model and the workflow of methods is performed again.

\section{Phase 4. Continuous documentation of all decisions and problems during the development process, using the DeCoDe model}

To validate the LIMs superiority, the stakeholder requirements were gathered and classified. Only relevant requirements were used as parameters through comparison using a Pughmatrix, as shown in Table 5. A Pugh-matrix compares one or more implementation concepts to a reference concept which is rated with 0 in every category [12]. A positive integer for the short-secondary LIM indicates a superiority of the LIM in this particular requirement. A negative integer indicates an advantage of the reference concept that is a conventional conveyor.

Table 5. Pugh-matrix to compare conventional conveyors and short-secondary LIM

\begin{tabular}{l|c|c}
\hline \multicolumn{1}{c|}{ Requirements } & Conventional conveyor & Short-secondary LIM \\
\hline Overcome distance & 0 & 0 \\
\hline Acceleration & 0 & 3 \\
\hline Velocity & 0 & 0 \\
\hline Position encoder & 0 & 0 \\
\hline Electrical brakes & 0 & 3 \\
\hline Mechanical brakes & 0 & -3 \\
\hline Starting under full-load & 0 & 0 \\
\hline Temperature & 0 & -3 \\
\hline Precision & 0 & 2 \\
\hline Investment costs & 0 & -2 \\
\hline
\end{tabular}




\begin{tabular}{l|l|l}
\hline Maintenance costs & 0 & 3 \\
\hline Energy costs & 0 & 0 \\
\hline Life span & 0 & 3 \\
\hline Load-bearing capacity & 0 & 3 \\
\hline Reliability & 0 & 3 \\
\hline Conditions of use & 0 & 0 \\
\hline Assembly & 0 & 0 \\
\hline Concept of control & 0 & 3 \\
\hline Functionality & 0 & 0 \\
\hline Safety & 0 & 3 \\
\hline Recycling & 0 & 0 \\
\hline Braking distance & 0 & 3 \\
\hline Sum & $\mathbf{0}$ & $\mathbf{2 1}$ \\
\hline
\end{tabular}

\section{Conclusion}

The project was able to verify and optimize the workflow of methods used in the development process. It could be shown that an early identification and modeling of specific system elements enables a more effective and reproducible use of simulations and methods. This can be used as a basis for an early reliability analysis.

It has to be added that additional research is needed regarding the transferability of properties and system elements between different concepts. Methods have to be created to formalize the transfer of resulting information between different systems.

Additionally valuable information regarding the usability of linear machines as conveyor drives could be gathered. While electrical linear drives are superior to rotational machines regarding the creation of translational force and life span, most variants of the linear drives suffer from either very high costs, are not suited for the transport of a wide range of conveyor goods (by using permanent magnets) or nullify the main advantage (very low maintenance) of linear drives by using trailing cables. Out of all variants, the short-secondary linear induction machine is the best suited drive for intralogistic systems despite the warming of the primary. It has to be added that an active cooling systems can't be considered, because it would negate the main advantage of the short-secondary linear induction motors. Nevertheless it could be shown that a passive cooling systems (cooling fins) is sufficient; it is possible to reduce the temperature to tolerable levels. Further narrowing the cooling fins enlarges the surface of the secondary even further thus resulting in maximized heat dissipation. In the worst case, the operating primary with a mechanical locked secondary, the secondary will be heated above permitted levels, due to the high eddy currents and the lower cooling mechanism and the lack of airstream cooling the secondary. An emergency system has to be installed, that shuts down activated primaries, if the secondary is blocked due to mechanical reasons. 
Finally, it was shown (Tab. 5) that the short-secondary is superior to the traditional rotating machines that are using gears and/or conveyor belts.

\section{References}

[1] Sitte J., Winzer P., Demand Compliant Design. IEEE Transactions on Systems, Man and Cybernetics, Part A 41 (2011)

[2] Winzer P., Kulig S., Methodenworkflow für die Zuverlässigkeit Vernetzter Mechatronischer Systeme. Sonderforschungsbereich 696 Forderungsgerechte Auslegung von intralogistischen Systemem - Logistics on Demand; Technische Universität Dortmund (2009).

[3] Riekhof F., Bielefeld O., Esser C., Winzer P., Anforderungen an intralogistische Systeme. ZWF Zeitschrift für wirtschaftlichen Fabrikbetrieb 10/2013, Carl Hanser Verlag (2013).

[4] Riekhof F., Winzer P., Wörner L., Kulig S., Funktionsorientierte Auslegung eines Linearantriebs. Conf. Entwurf komplexer Automatisierungstechnik EKA 2012, Magdeburg, pp. 121-138 (2012).

[5] Duncan J., Eng C., Linear induction motor - equivalent circuit model. IEE PROC. 130B(1): 51-57 (1983).

[6] Riekhof F., Winzer P., Wörner L., Kulig S., Ansatz zur lösungsneutralen Funktionsmodellierung für das Komplexitätsmanagement und Zuverlässigkeitsanalysen bei mechatronischen Systemen. VDIGesellschaft Produkt- und Prozessgestaltung, 26. Fachtagung Technische Zuverlässigkeit 2013. Entwicklung und Betrieb zuverlässiger Produkte, VDI-Berichte 2210, Düsseldorf, pp. 63-76 (2013).

[7] Chakrabarti A., Engineering Design Synthesis: Understanding, Approaches and Tools. Springer Ver$\operatorname{lag}(2002)$.

[8] Koller R., Kastrup N., Prinziplösungen zur Konstruktion technischer Produkte. 2. Auflage, Springer, Berlin Heidelberg (2008).

[9] Riekhof F., Willing M., Ableitung von Kausalketten für Fehlerfolgeanalysen aus Systemmodellen am Beispiel eines Linearantriebs. Von der Produktentwicklung bis zum Business Excellence (Berichte zum Generic-Management, 2013, (4); Shaker, Aachen (2013).

[10]ISO, Road vehicles - Functional safety. ISO 26262 (2011).

[11] Rosendahl J., Kulig S., Schlund S, Winzer P., Methodenworkflow zur Entwicklung mechatronischer Systeme. 3. Kolloquium Forderungsgerechte Auslegung von intralogistischen Systemen. Logistics on Demand, Verlag Praxiswissen, pp.63-79 (2009).

[12] Lunau S., Staudter C, Meran R. et al., Design for Six Sigma + Lean Toolset - Implementing Innovations Successfully. Springer Vieweg Verlag (2009). 